\title{
Current Interferometry Results in Canada
}

\author{
Ian G. Cumming Senior Life Member, IEEE, Bernhard Rabus (MDA) and Bryan Mercer (Intermap) \\ Radar Remote Sensing Group \\ Department of Electrical and Computer Engineering, Univ. of British Columbia \\ 5500-2332 Main Mall, Vancouver, BC, Canada V6T 1 Z4 \\ phone: +1 604221 1114, email: ianc@ece.ubc.ca
}

\begin{abstract}
A number of groups are currently active in radar interferometry in Canada, including government institutions, universities and industry. This paper will present a survey of interferometry applications in Canada, and illustrate recent results.

In the airborne radar domain, early research with the Canada Centre for Remote Sensing (CCRS) Convair-580, has led to successful commercial programs at MacDonald Dettwiler (MDA) and Intermap Technologies. MDA has built three single-pass interferometers that are in operational use in the Amazon basin, and Intermap have built five systems that are producing DEMs with 1-m vertical accuracy.

On the satellite front, RADARSAT-1 data has been used for repeat pass mapping in the Canadian Arctic. A number of subsidence and landslide sites are being continually monitored with the permanent scatterers technique. A 3-satellite constellation, the RADARSAT Constellation Mission, will support Future InSAR applications.
\end{abstract}

Index Terms-Synthetic Aperture Radar (SAR), Interferometry, mapping, landslides, land subsidence, permanent scatterers.

\section{INTRODUCTION}

In this survey paper, we review some of the historical and current work on interferometry in Canada. Examples involve mapmaking from satellite and airborne platforms, permanent scatterers for deformation monitoring, and the proposed future use of the RADARSAT Constellation Mission.

\section{INTERFEROMETRY IN THE CANADIAN GOVERNMENT}

\section{A. Canada Centre for Remote Sensing}

CCRS has been a pioneer in cross-track and along-track interferometry, beginning with data from the Convair-580 (Figure 1), which was the first system to demonstrate airborne repeat-pass interferometry for height and current measurements. Repeat-pass ocean current measurements in the Bay of Fundy are illustrated in Figure 2.

When a second cross-track InSAR antenna was added to the Convair-580, interesting single-pass airborne interferometry results were obtained over mountainous terrain and Arctic glaciers. Figure 3 shows a perspective view of the ski area in the Kananaskis Valley used for the 1988 Winter Olympics, with elevations between 1430 and $2730 \mathrm{~m}$. Figure 4 shows the large Sermilik Glacier on Bylot Island at $73^{\circ} \mathrm{N}, 78^{\circ} \mathrm{W}$, flowing into the Arctic Ocean. The glacier has retreated over $2 \mathrm{~km}$ since the image was taken in October 1992.

On the satellite front, early repeat-pass ERS data were used to make accurate glacier flow measurements [1] and

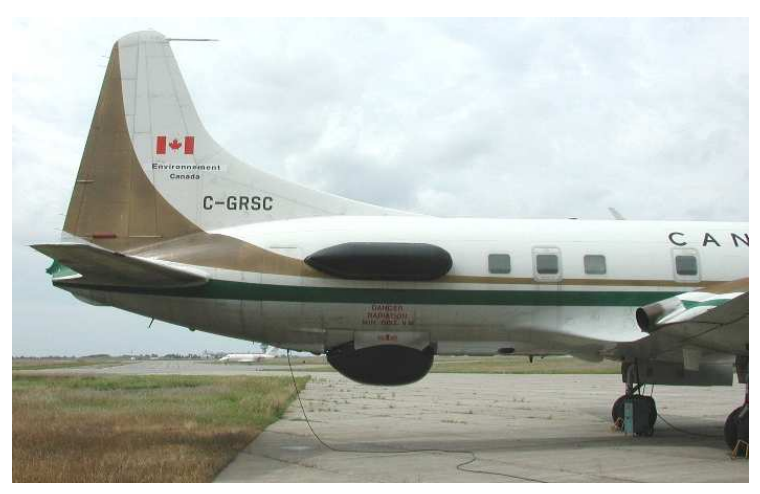

Fig. 1. Cross-track C-band InSAR antennas on the Canadian Convair-580.

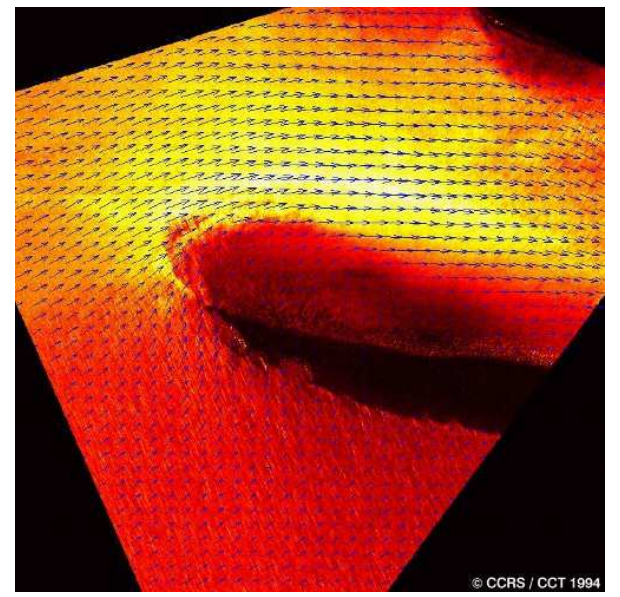

Fig. 2. InSAR ocean current measurements from the Convair-580.

RADARSAT- 1 data were used to measure Antarctic Ice Flow [2], [3].

As satellite repeat-pass interferometry is limited by the coherence between passes, results are restricted to those areas of the world where the scattering mechanisms are very stable over the observation period. This is especially true of the RADARSAT-1 satellite, which has a rather long repeat cycle of 24 days.

As a result, RADARSAT-1 has found few interferometric mapping applications. One notable success has been experienced in the Canadian Arctic, where the arid conditions allow good coherence over the 24-day interval. Figures 5 and 6 give results of Bathurst Island at $76^{\circ} \mathrm{N}$, where excellent coherence produced a good-quality interferogram [4]. Also, it has shown to be possible to get useful interferometry results 


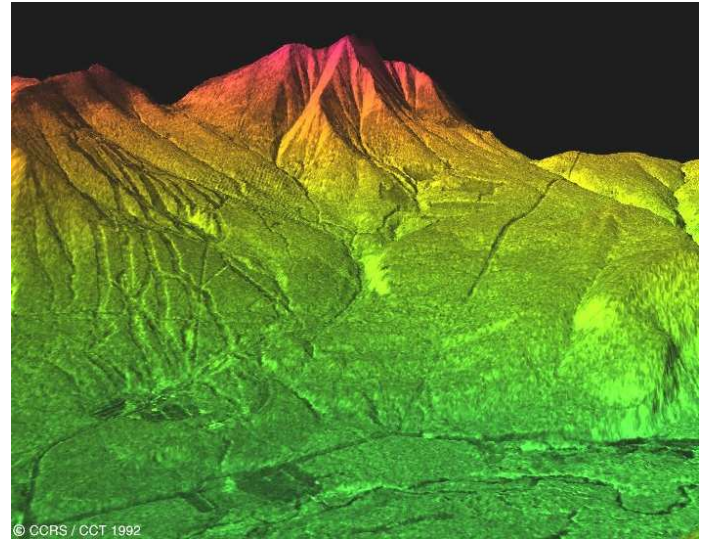

Fig. 3. Perspective of Mount Allan rendered by the CCRS InSAR system.

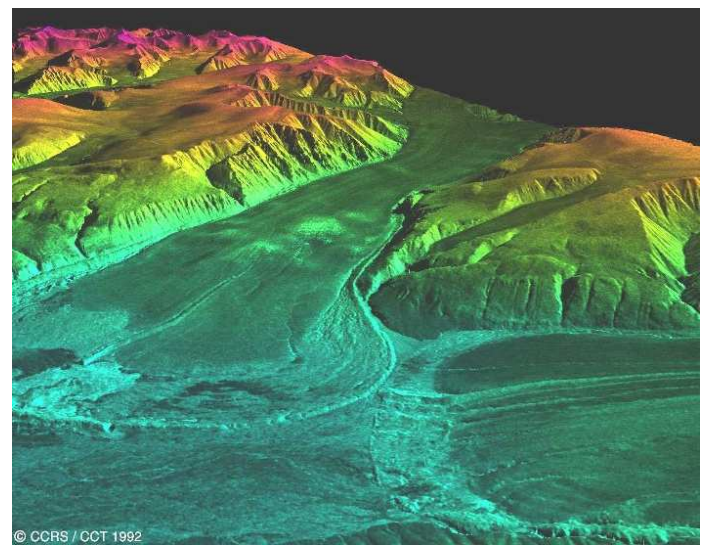

Fig. 4. InSAR view of mountains and glaciers on Bylot Island.

from RADARSAT-1 ScanSAR data [5].

Perhaps the most successful interferometry technique with RADARSAT data in Canada is permanent scatterers - see Section III-B).

\section{Geohazard Monitoring with Coherent Targets}

Permanent Scatterer Interferometry (PS-InSAR) is used to provide enhanced ground deformation mapping compared with standard differential interferometry. PS-InSAR uses a larger dataset that allows estimation through regression analysis of a number of phase errors from sources like height inaccuracy and sub-pixel position of the scatterer. This work shows the benefits of a good quality DEM and of the detection of high quality coherent targets (vs. distributed targets) for landslide monitoring.

One application of PS-InSAR in Canada is the geohazard sites in the Rocky Mountains. These sites are characterized by steep relief and an abundance of radar shadows and foreshortening that would complicate the spatial phase unwrapping process. In this case, detecting individual point scatterers and unwrapping the phase in time instead of space can overcome these complications. An example of this technique is presented in Figure 7, which shows a color map of the estimated yearly linear deformation rates of the detected targets of the Frank slide in SW Alberta [6]. To obtain this result, a set of permanent targets where detected using a time coherence estimator and a linear deformation model. Afterwards, DEM

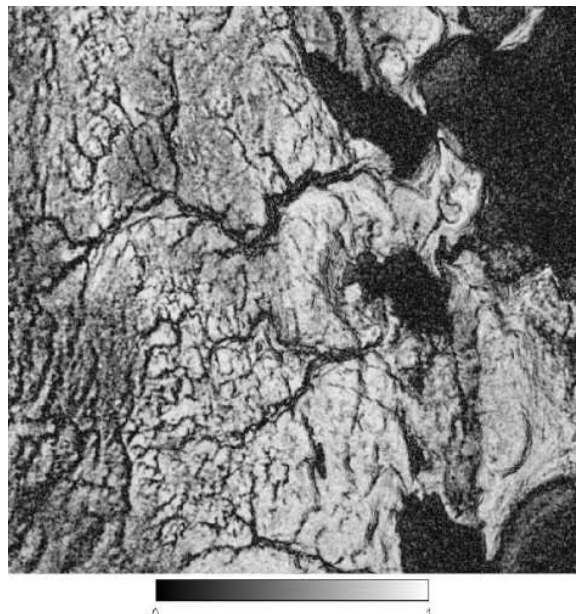

Fig. 5. RADARSAT-1 repeat pass coherence map of Bathurst Island.

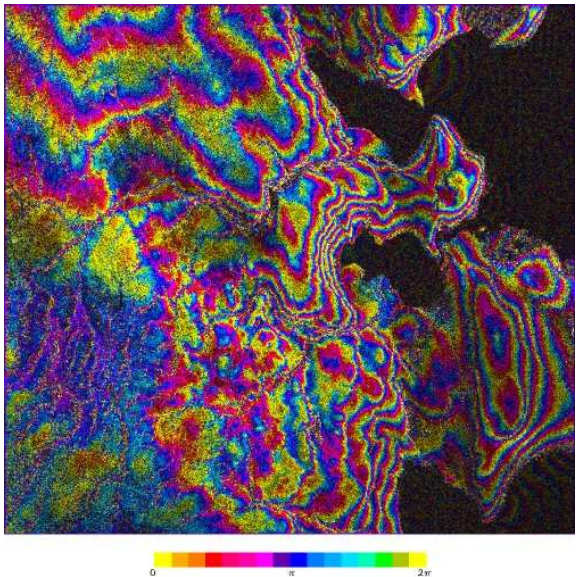

Fig. 6. RADARSAT-1 repeat pass interferogram of Bathurst Island.

errors and subpixel target positions in the slant range direction were corrected using regression analysis.

Temporal decorrelation in the highly vegetated Rocky Mountains is also expected. In these conditions, isolated permanent scatterers have to be detected and used for monitoring and PSI seem to be again the best choice. The detected natural targets should be characterized by an intermediary level of signal to clutter ratio, superior to the surrounding clutter but somewhat inferior to a corner reflector.

The Frank Slide results show an accuracy within the range expected from the error model [7]. It was found that 15 data sets are recommended for accuracy - so landslide monitoring will be significantly enhanced by the 4-day repeat RADARSAT Constellation Mission.

\section{Subsidence Mapping}

In another current project, PS-InSAR has been used by the Geological Survey of Canada to measure uplift in the Fraser Valley flood plain. The primary objective is to quantify the ongoing subsidence of the Fraser Delta area related to natural and amplified Holocene sediment compaction. Subsidence of the Fraser Delta is of particular importance for quantifying future sea-level rise hazards.

By processing ERS-1 and -2 data with Coherent Target Monitoring (CTM-InSAR) software, it was found that the 


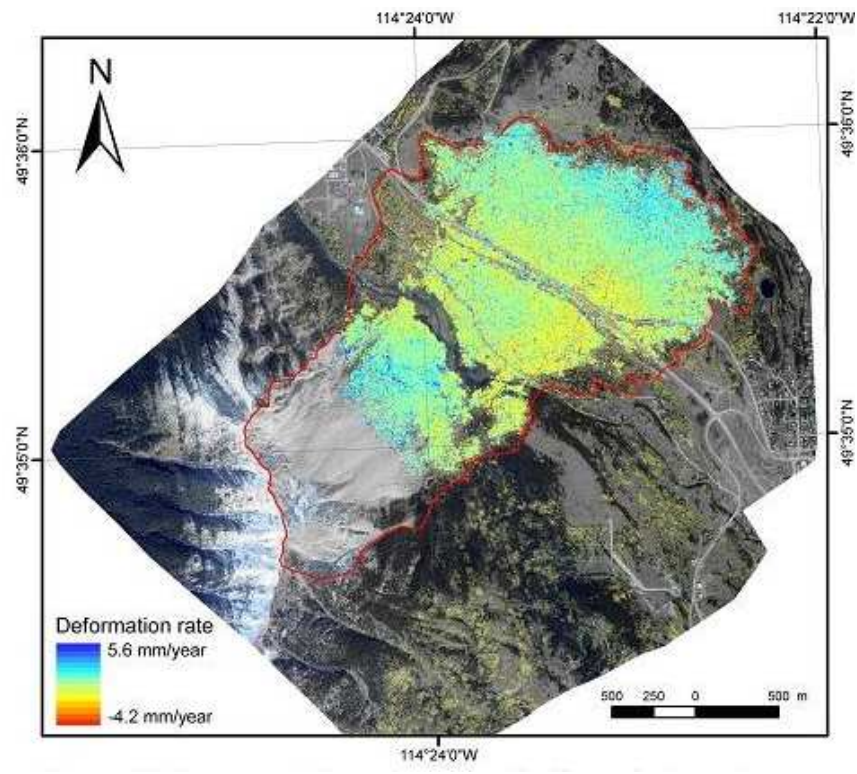

Fig. 7. Deformation rates of the detected targets in the Frank slide.

Fraser Delta lowland is subsiding at $1-2 \mathrm{~mm} / \mathrm{yr}$ relative to the nearby highlands in Vancouver and Burnaby (Figure 8, courtesy of Stéphane Mazzotti, GSC). In some areas, subsidence can be as large as $3-8 \mathrm{~mm} / \mathrm{yr}$ due to recent construction load-induced compaction. The implication is that, by 2100 , the Fraser Delta will see an extra 10-20 cm of relative sea-level rise above the oceanic-only $20-50 \mathrm{~cm}$ rise [8].

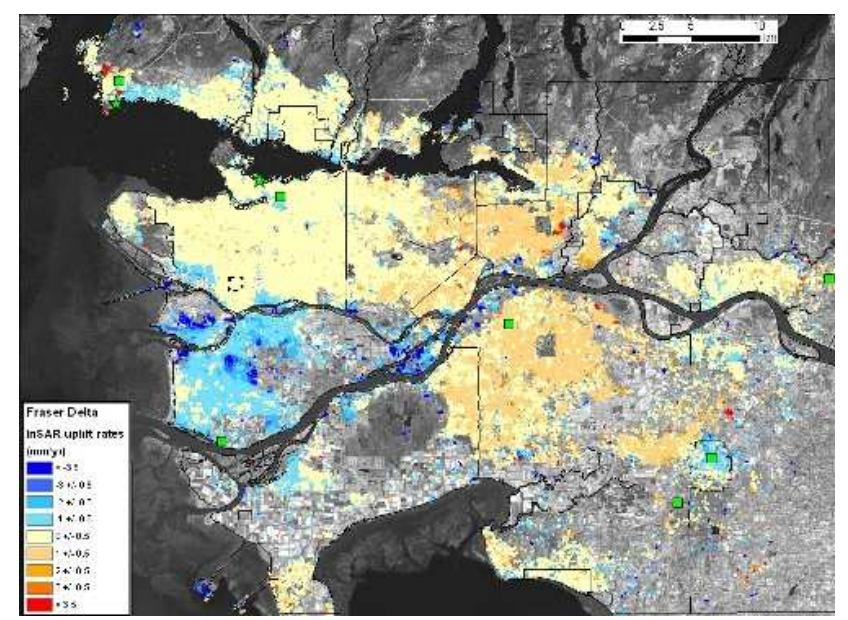

Fig. 8. Deformation rates in the Fraser Valley, British Columbia (mm/a).

\section{B. Defence Research and Development Canada}

A recent Canadian Defence study examined the potential applications of polarimetric SAR interferometry (Pol-InSAR), which combines the resources of polarimetric SAR for target classification with the capability of interferometric SAR for height discrimination.

Two field trials in Ottawa and Petawawa collected PolInSAR data using the Environment Canada's Convair-580 in repeat-pass mode. Calibration, processing and analysis of the data were completed, and potential application have been anal- ysed in view of the upcoming RADARSAT-2 and PALSAR missions [9].

\section{Canadian Space Agency}

The Canadian Space Agency (CSA) has initiated the development of a low-cost small-satellite C-band SAR constellation as a follow-on project to the RADARSAT-2 program. The lowcost concept requires that the SAR system design is in terms of mass, power consumption, volume, and antenna size, in compliance with the constrains set by using a low-cost launch vehicle and a small satellite bus [10].

The RADARSAT Constellation Mission (RCM) consists of a three spacecraft fleet of Earth observation satellites (Figure 9). The system will be capable of imaging all of Canada's land and water areas daily at a resolution of $50 \mathrm{~m}$, and provide enhanced coverage of $95 \%$ of the world. The orbital altitude will be $600 \mathrm{~km}$, giving a 4-day repeat cycle for better repeatpass interferometry. With satellites smaller than RADARSAT2 , the RCM will provide new interferometric applications made possible through the constellation approach - as well as continuing to provide $\mathrm{C}$ band radar data to RADARSAT- 2 users [11].

Currently (October 2007), MacDonald Dettwiler has completed the Phase A feasibility study of the constellation, and Bristol Aerospace is designing the small satellite bus. The small satellite bus will have a mass of $1300 \mathrm{~kg}$, average power of $220 \mathrm{w}$, and a $9.5 \mathrm{~m}^{2} \mathrm{SAR}$ antenna. The contract for the detailed design is expected to be awarded in 2008 [12].

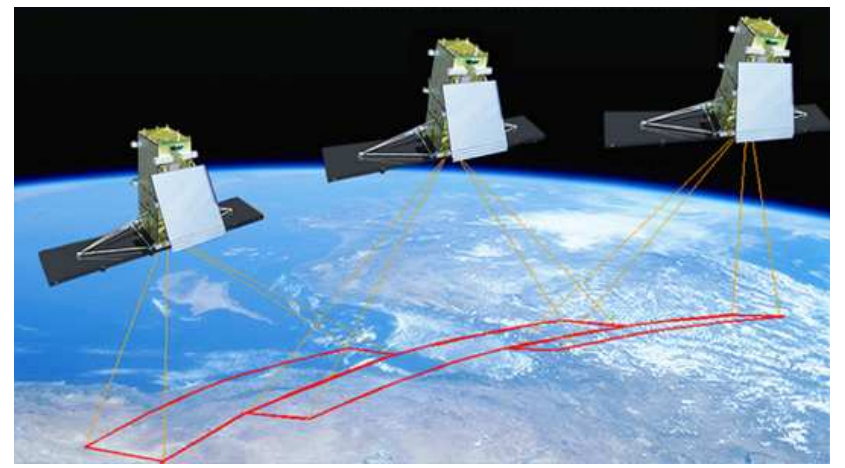

Fig. 9. Sketch of the planned RADARSAT Constellation Mission.

\section{INTERFEROMETRY IN CANADIAN INDUSTRY}

\section{A. Intermap Technologies}

Intermap technologies are currently operating 4 airborne interferometric systems built in Canada and Germany (Figures 10 and 11). Their operational role is to generate height maps with a vertical accuracy of $1 \mathrm{~m} \mathrm{rms}$ and a posting of $5 \mathrm{~m}$. Currently, much of the USA, Britain and Germany have been mapped with these radars, and further mapping is being done on an operational basis every day [13].

Figure 12 shows a DEM of all of California - the vertical accuracy has been validated using 1430 check points and found to be $0.76 \mathrm{~m}$ RMS. Examples of applications include flood prediction (Figure 13). 


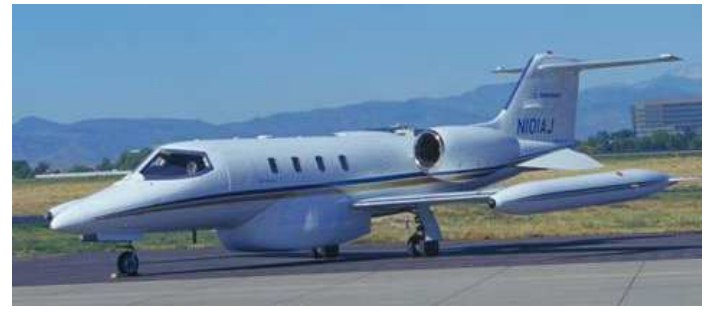

Fig. 10. The Intermap STAR-3i system installed on a Learjet 36.

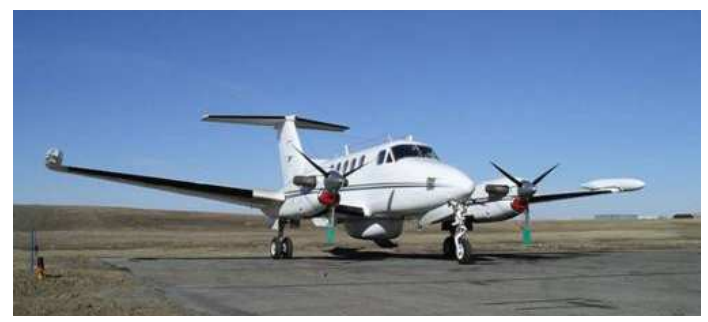

Fig. 11. The Intermap STAR-4 system on a King Air 200T.

A fifth airborne system, TopoSAR, supports repeat-pass, fully polarized P-Band InSAR as well as a single-pass Xband InSAR. It is currently being used mainly as a research platform. Currently, Intermap is modifying the TopoSAR system to enable single-pass, L-Band, fully polarimetric InSAR acquisition, in order to test the effectiveness of PolInSAR for extracting bare-earth DEMs beneath forest canopy. Results are expected in early 2008.

\section{B. MacDonald Dettwiler's Satellite InSAR Projects}

MacDonald Dettwiler (MDA) has developed an in-house automated PS-InSAR solution on top of Gamma Remote Sensing software packages ISP and MSP, and has recently added the Coherent Target Monitoring developed by Atlantis/Vexcel (now MDA) as a further powerful interactive service solution.

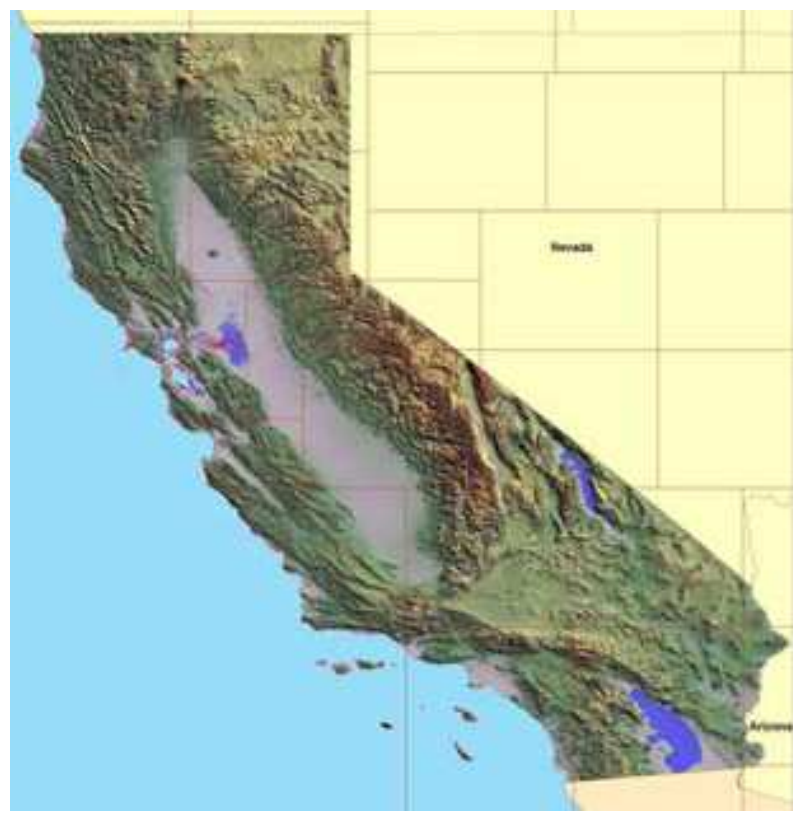

Fig. 12. NextMap DEM of California produced by Intermap.

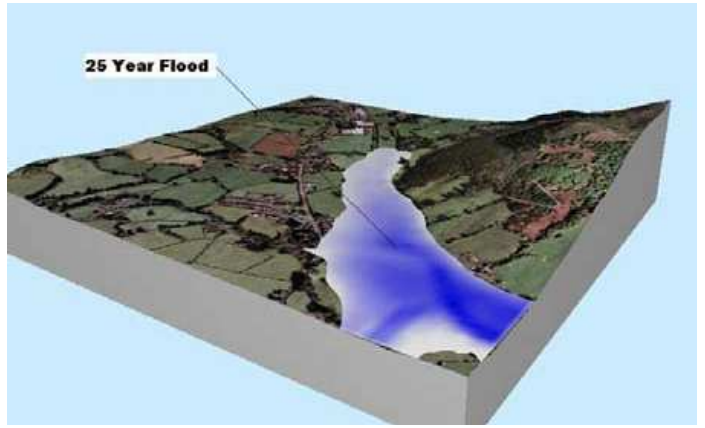

Fig. 13. Flood extent prediction based on Intermap DEMs.

Typical applications are reconnaissance and monitoring of geophysical and manmade hazards for the oil/gas and mining industries, as well as risk analyses for decision makers and the insurance market. A further important market is detection and monitoring of subsidence for military and security applications.

The MDA solutions are operational with RADARSAT-1, ERS and ENVISAT data. One of several land subsidence sites currently monitored in Canada and the US [14] is the Cold Lake Heavy Oil Field, Alberta, Canada, where the subsidence is a function of the amount of oil extracted from the underground reservoirs (Figure 14).

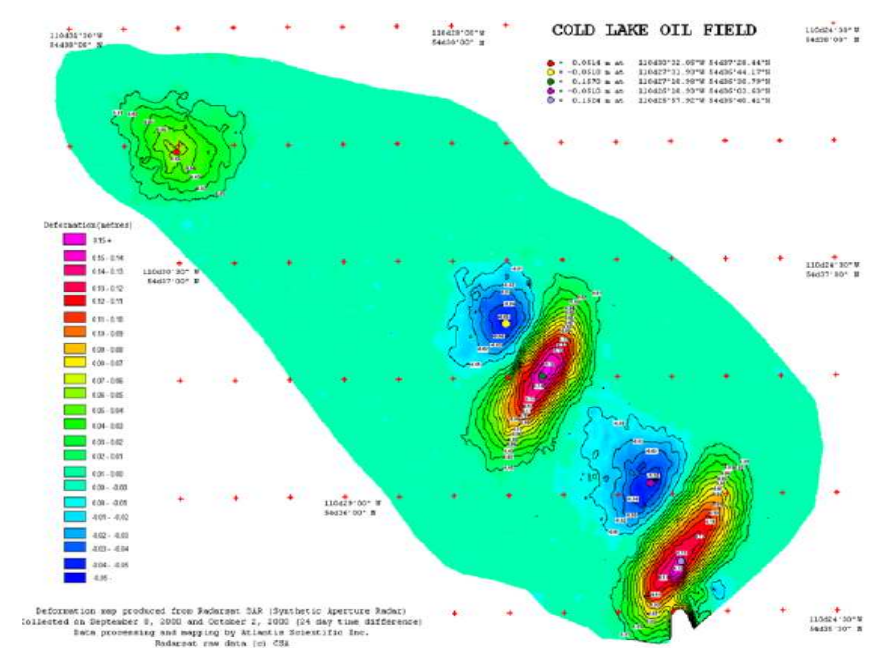

Fig. 14. RADARSAT-1 subsidence measurements of an oil field in Alberta.

In other examples, MDA is monitoring an oil pipeline with InSAR for the Brazilian oil company, Petrobras, and is measuring subsidence in downtown Los Angeles (see Figure 15, where the PS locations and values are overlaid on Google Earth [15]).

\section{MacDonald Dettwiler's Airborne InSAR Projects}

MacDonald Dettwiler have two airborne interferometry projects, the CP-140 project for the Dept. of National Defence and the SIVAM project for the Brazil Coast Guard. The CP140 is a multi-mode, high-resolution SAR that includes moving target detection based on the along-track interferometry principle. The system is currently undergoing flight trials. 


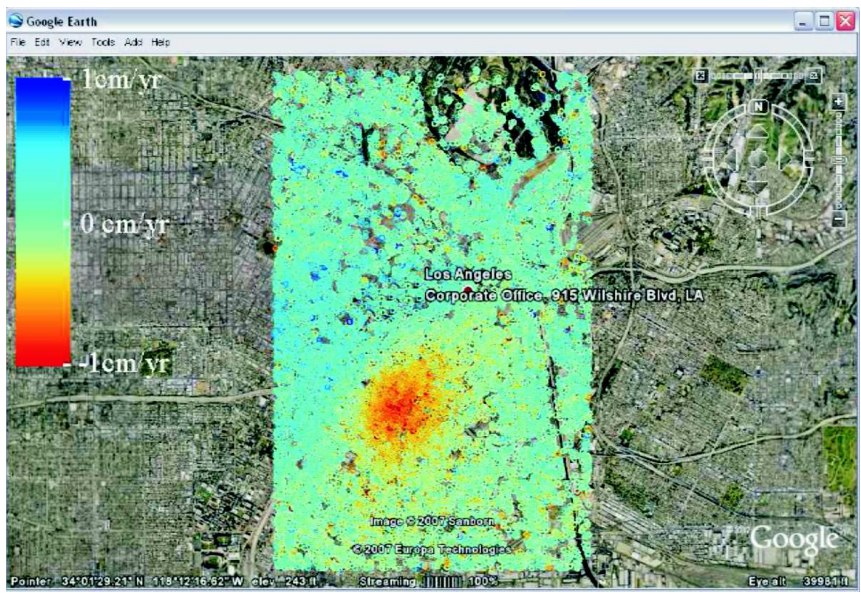

Fig. 15. RADARSAT-1 subsidence measurements in the city of Los Angeles.

The SIVAM radar has recently been installed on three Embraer 145 aircraft (Figure 16). It has an L-band polarimetric radar and an X-band cross-track interferometric system. The $\mathrm{X}$-band system has a strip-map resolution of $3 \mathrm{~m}$, and a spotlight resolution of $1.8 \mathrm{~m}$. There is real-time processing on-board for pass verification, and precision processing on the ground for interferometric map-making.

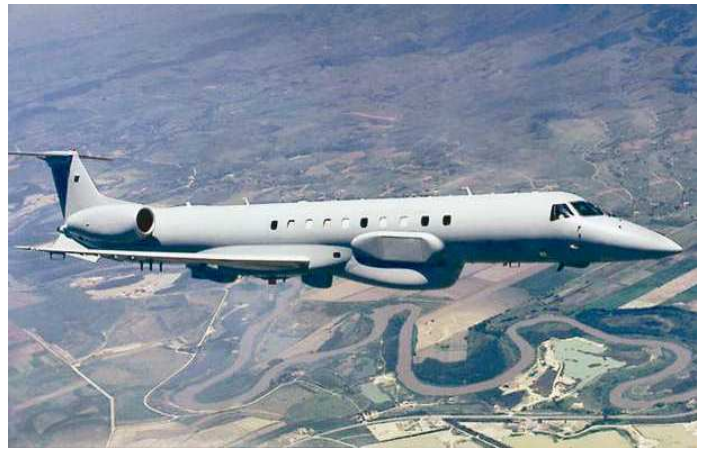

Fig. 16. X-band InSAR system installed on the SIVAM Embraer 145 aircraft.

The X-band interferometer operates in strip-map mode, and the data are low-pass filtered to a pixel spacing of $5 \times 5 \mathrm{~m}$ before the interferogram processing. An example of a height map is given in Figure 17. It covers part of the bayou area of New Orleans, with a height scale of zero to $5 \mathrm{~m}$. For comparison, the corresponding Google Earth image is shown in Figure 18. The scene center is $29.994^{\circ} \mathrm{N}, 91.417^{\circ} \mathrm{W}$ with an orientation of $92^{\circ}$.

\section{INTERFEROMETRY IN CANADIAN UNIVERSITIES}

\section{A. McMaster University}

A number of projects at Canadian universities are aimed at using RADARSAT data for geographical and ecological applications. One example comes from the School of Geography and Earth Sciences at McMaster University, where they have been comparing two methods of DEM generation of a very deep river valley in southern Alberta [16].

It was found that RADARSAT-1 satellite interferometry gave the best definition of valley shape after correcting for

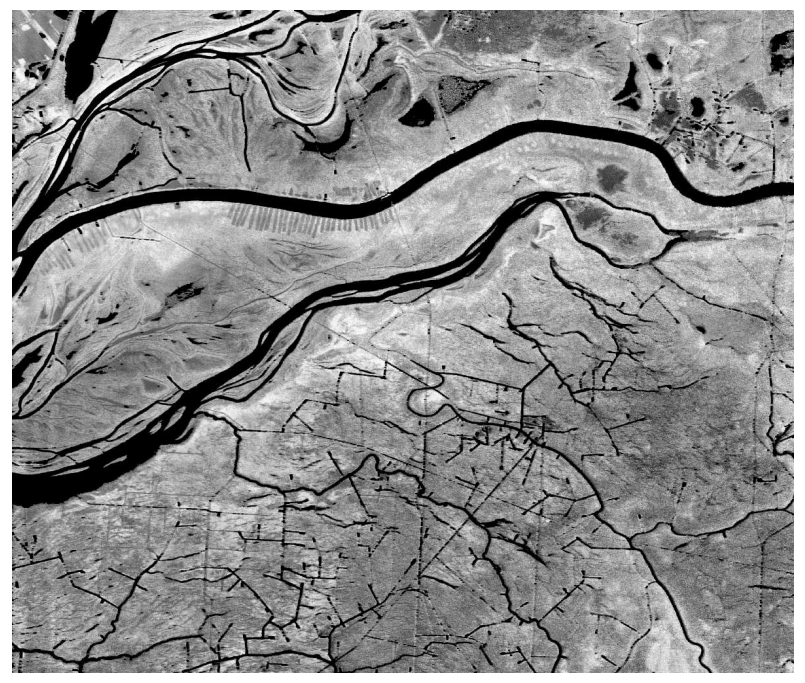

Fig. 17. SIVAM height map of the bayou area near New Orleans.

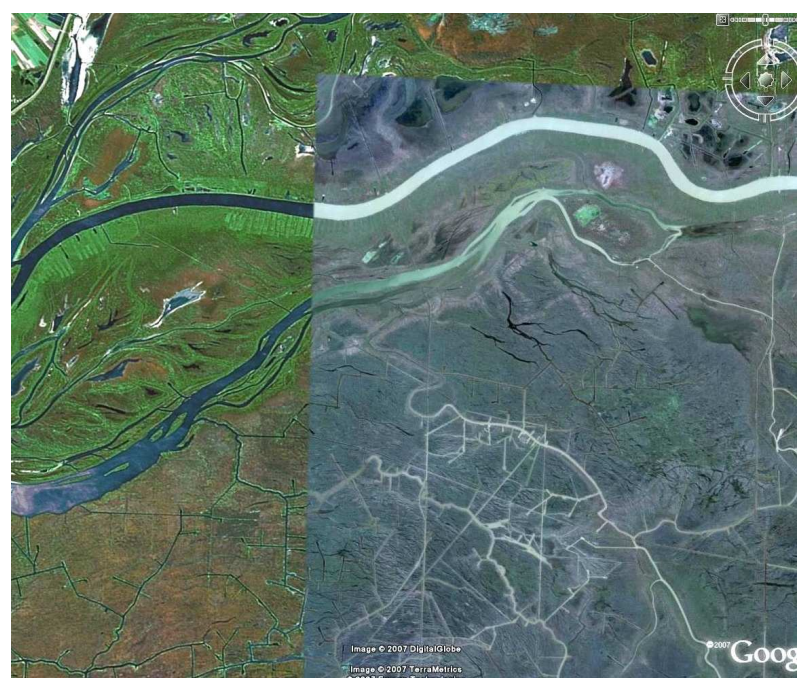

Fig. 18. Google Earth comparison of the SIVAM height map.

the viewing angle effects, compared with radar altimetry or SRTM. The image of Figure 19 contains elevation textures related to varying crop heights in adjacent fields. This level of resolution was not achievable with radar altimetry or the SRTM data set.

\section{CONCLUSIONS}

Canada has been a leader in interferometry development since experiments began with the Convair-580 SAR in the 1980's. The developments have led to current operational airborne and satellite height and deformation mapping systems that are the equal of any in the world today. It is hoped that the future RADARSAT Constellation Mission will extend this trend into the next decade.

\section{REFERENCES}

[1] K. E. Mattar, P. W. Vachon, D. Geudtner, A. L. Gray, I. G. Cumming, and M. Brugman. Validation of alpine glacier velocity measurements using ERS Tandem-Mission SAR data. IEEE Trans. Geoscience and Remote Sensing, 36(3):pp. 974-984, May 1998. 


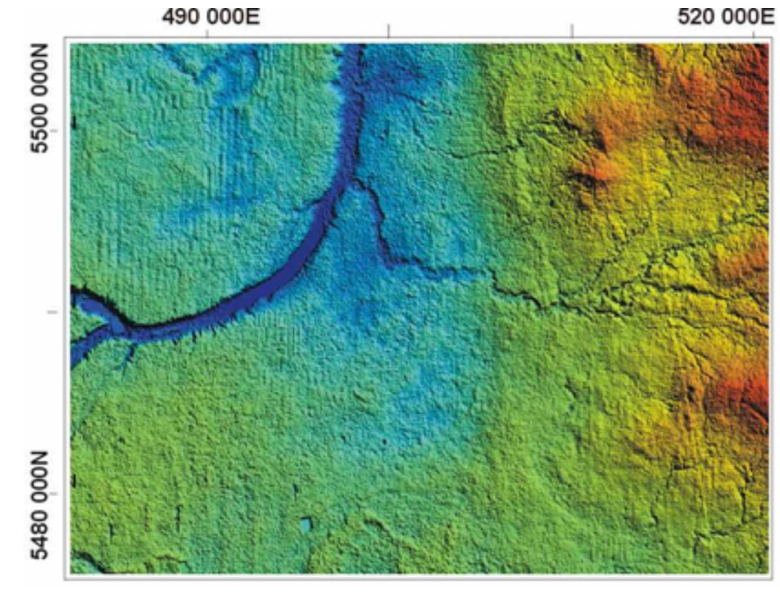

Fig. 19. Repeat-pass InSAR height map of valley in Alberta.

[2] A. L. Gray, K. E. Mattar, P. W. Vachon, R. Bindschadler, K. C. Jezek, R. Forster, and J. P. Crawford. InSAR results from the RADARSAT Antarctic Mapping Mission data: estimation of glacier motion using a simple registration procedure. In Inter. Geoscience and Remote Sensing Symp., IGARSS'98, Seattle, July 1998.

[3] L. Gray, I. Joughin, S. Tulaczyk, V. Spikes, R. Bindschadler, and K. Jezek. Evidence for subglacial water transport in the West Antarctic Ice Sheet through three-dimensional satellite radar interferometry. Geophysical Research Letters, 32, February 8, 2005.

[4] D. Geudtner, P. W. Vachon, K. E. Mattar, B. Schaettler, and A. L. Gray. Interferometric Analysis of RADARSAT Strip-Map Mode Data. Canadian J. of Remote Sensing, 27(2):pp. 95-108, April 2001.

[5] R. Bamler, D. Geudtner, B. Schattler, P. Vachon, U. Steinbrecher, J. Holzner, J. Mittermayer, H. Breit, and A. Moreira. RADARSAT ScanSAR Interferometry. In Inter. Geoscience and Remote Sensing Symp., IGARSS'99, pages pp. 1517-1521, Hamburg, 28 June 28-July 2, 1999.

[6] V. Poncos, S. Mei, and V. Singhroy. Point Target Interferometry for Natural and Artificial Scatterers. In Inter. Geoscience and Remote Sensing Symp., IGARSS'07, Barcelona, July 23-27, 2007.

[7] S. Mei, V. Poncos, and C. Froese. InSAR Mapping of Millimeterscale Ground Deformation over Frank Slide, Turtle Mountain, Alberta. EUB/AGS Earth Science Report, Alberta Energy and Utilities Board, in press, 2007.

[8] A. Lambert, S. Mazzotti, M. van der Kooij, and A. Mainville. Subsidence and Relative Sea Level Rise in the Fraser River Delta, Greater Vancouver, British Columbia, from Combined Geodetic Data. Technical report, Geological Survey of Canada, Open File, 5698, 2007.

[9] Karim Mattar, Chen Liu, and Ramin Sabry. Polarimetric SAR Interferometry: Investigations using EC CV-580 SAR Data. Technical report, Defence Research and Development Canada (Ottawa), 2006.

[10] Ralph Girard, Patrick Plourde, and Guy Séguin. The RADARSAT Constellation Payload Design. In Inter. Geoscience and Remote Sensing Symp., IGARSS'07, Barcelona, July 23-27, 2007.

[11] Dirk Geudtner and Guy Séguin. Application Potentials of the planned RADARSAT Constellation. In Inter. Radar Symp., IRS 2007, Cologne, September 5-7, 2007. German Institute of Navigation (DGON).

[12] RADARSAT Constellation. Canadian Space Agency, October 2007. http://www.space.gc.ca/asc/eng/satellites/radarsat/.

[13] Bryan Mercer. National And Regional Scale DEMs Created From Airborne InSAR. In U. Stilla, editor, International Archives of Photogrammetry, Remote Sensing and Spatial Information Sciences, Photogrammetric Image Analysis, Munich, Germany, September 19-21, 2007.

[14] M. van der Kooij and D. Mayer. The application of satellite radar interferometry to subsidence monitoring in the Belridge and Lost Hills fields, California. In Inter. Geoscience and Remote Sensing Symp., IGARSS'02, Toronto, June 24-28, 2002.

[15] Bernhard Rabus and Bert Kampes. InSAR Monitoring with Artificial and Pre-Existing Persistent Scatterers. In Advanced SAR Workshop 2007, Vancouver, September 11-13, 2007. Canadian Space Agency.

[16] Kristi Markham and William Morris. A Comparison Of Radar Altimetry And Repeat Pass Interferometry As Methods Of Producing Digital
Terrain Elevation Models. In Inter. Geoscience and Remote Sensing Symp., IGARSS'02, Toronto, June 24-28, 2002. 